\title{
Physical and Genetic Characterization of Chromosomal Copies of the Streptomyces coelicolor Mini-circle
}

\author{
By DEREK J. LYDIATE, ${ }^{*} \dagger$ ALISON M. ASHBY, $\ddagger$ \\ DUNCAN J. HENDERSON, HELEN M. KIESER AND \\ DAVID A. HOPWOOD \\ John Innes Institute and AFRC Institute of Plant Science Research, Norwich NR4 7UH, UK
}

(Received 20 June 1988; revised 14 November 1988; accepted 13 December 1988)

\begin{abstract}
The two linear, integrated mini-circle copies of Streptomyces coelicolor A3(2) were cloned in Escherichia coli and their positions on the $S$. coelicolor genetic map were determined. Mini-circle copy $\mathrm{A}$ is close to the $\arg A$ locus, $20 \mathrm{~kb}$ upstream of the $g y l$ operon. Mini-circle copy B is close to the cys $D$ locus and is absent from $S$. coelicolor $\mathrm{J} 1501$, which has suffered a chromosomal deletion including mini-circle copy $B$ and possibly associated with the $p g l$ mutation. The mini-circle copies were not involved in any of the several previously identified physical interactions between the plasmid SCP1 and the $S$. coelicolor chromosome. A new insertion sequence was identified close to the right end of mini-circle copy B in $S$. coelicolor M145. The free mini-circle of $S$. coelicolor, when inserted into an attP-deleted derivative of phage $\phi \mathrm{C} 31$, actively integrated this phage into the chromosomes of $S$. coelicolor and $S$. lividans at preferred and secondary sites. The resulting prophages were stably inherited and remained physically intact. No precise excision of prophages from $S$. lividans lysogens carrying insertions at preferred or secondary integration sites was detected: instead, free phages were generated by imprecise excisions. These phages allowed the in vivo cloning of segments ( $>3 \mathrm{~kb}$ in length) of the chromosomal DNA flanking preferred and secondary integration sites. Attempts to delete the preferred integration site by double homologous recombination with a clone carrying flanking DNA sequences and an antibiotic resistance gene were unsuccessful.
\end{abstract}

\section{INTRODUCTION}

The $2.6 \mathrm{~kb}$ mini-circle sequence of Streptomyces coelicolor A3(2) exists in the $S$. coelicolor genome as two linear, integrated copies (A and B) and also as free mini-circles with a copy number of less than one per ten genomes (Lydiate et al., 1986). Mini-circle functions actively integrate phage $\mathrm{KC} 591$ (an attP-deleted phage $\phi \mathrm{C} 31$ derivative carrying a cloned free minicircle) into the genomes of many Streptomyces strains. In $S$. lividans this integration is most often at a preferred site but also occurs at secondary sites. The biological properties of the mini-circle, including the mechanism of its integration, the randomness or otherwise of potential host insertion sites and the ability of linear mini-circle copies to excise (precisely or imprecisely), are obviously worthy of investigation.

Several genetic properties of the $S$. coelicolor host of the $2.6 \mathrm{~kb}$ mini-circle are likely to involve endogenous transposable elements. Interactions of plasmid SCP1 with various regions of the $S$. coelicolor chromosome caused the formation of highly fertile donor strains and SCP1'

† Present address: Institute of Plant Science Research, Cambridge Laboratory, Maris Lane, Cambridge CB2 2JB, UK.

$\ddagger$ Present address: Department of Botany, University of Cambridge, Cambridge, UK. 
plasmids (Vivian \& Hopwood, 1973; Hopwood \& Wright, 1976a; Hopwood et al., 1984). By analogy with the formation of Hfr strains in Escherichia coli (Deonier \& Hadley, 1980; Guyer $e t$ al., 1980) these interactions probably involved transposable elements. Indeed, an insertion sequence has recently been implicated in the integration of SCP1 into the $S$. coelicolor chromosome which yielded the NF fertility type (Kendall \& Cullum, 1986). The $p g l$ locus of $S$. coelicolor (which is involved in host resistance to infection by phage $\phi \mathrm{C} 31$ ) is unstable, mutating and reverting at high frequencies (Chinenova et al., 1982). DNA rearrangements might account for this instability and mini-circle copy B was absent from the $p g l$ mutant strain J1501 but conserved in all $\mathrm{pgl}^{+} S$. coelicolor strains investigated, including strain $\mathrm{M} 130$, the direct progenitor of J1501 (Lydiate et al., 1986).

The mini-circle sequence of $S$. coelicolor may function as an effective vector for the stable, unit copy cloning of genes in Streptomyces. Integration of KC591 into many Streptomyces strains (Lydiate et al., 1986) demonstrated the ability of the mini-circle to integrate a $40 \mathrm{~kb}$ insert into a wide range of hosts, and the mini-circle-directed integration of pIJ4210 (a pBR327 derivative carrying a mini-circle linearized at the HindIII site and a $t s r$ gene for thiostrepton resistance) into the preferred site of $S$. lividans (Lydiate et al., 1987) demonstrated that $S$. lividans can be efficiently transformed by mini-circle DNA isolated from E. coli and possessing no Streptomyces replicon.

Transposable elements that function as effective insertional mutagens have been very useful in molecular investigations of many organisms, facilitating the cloning and genetic mapping of mutated genes. Two derivatives of the $2.6 \mathrm{~kb}$ mini-circle, phage KC591 and E. coli plasmid pIJ4210, are potential insertional mutagens for the genus Streptomyces. They carry antibiotic resistance markers and are actively integrated into Streptomyces chromosomes by their cloned mini-circle copies (Lydiate et al., 1986, 1987). However, in order to be useful mutagens these mini-circle derivatives must be able to insert into host genomes at very many different sites.

We report here the cloning of the two linear, integrated mini-circle copies of $S$. coelicolor, together with the mini-circle/chromosome junctions of integrated KC591 prophages. Linear mini-circle copies A and B were located on the $S$. coelicolor genetic map and any involvement of the mini-circle in the generation of $S$. coelicolor donor types or the instability of the $\mathrm{Pgl}$ phenotype was investigated. A study of the excision of KC591 prophages from $S$. lividans and attempts to isolate mini-circle-induced mutations in $S$. lividans and to delete the preferred site of mini-circle integration from $S$. lividans are also described.

\section{METHODS}

Bacterial strains, plasmids and bacteriophages. Streptomyces strains are listed in Table 1. E. coli strains F- lacZ $\Delta$ M15 recA (Rüther et al., 1981), ED8767 (Murray et al., 1977) and GM242 (dam-3 recA rpsL: M. G. Marinus, personal communication) were used as plasmid hosts. Plasmids and phages are listed in Table 2.

Culture conditions, genetic techniques and transformation. General culture conditions and genetic techniques for Streptomyces strains and phages were as described by Hopwood et al. (1985). Selenate-resistant mutants were selected on MM-S medium containing glutathione $(0.2 \mathrm{mM})$ and selenate $(5 \mathrm{mM})$ as described by Lydiate et al. (1988); 2-deoxyglucose-resistant mutants were selected on NMM medium containing arabinose (25 mM) and 2deoxyglucose $(50 \mathrm{mM})$ as described by Hodgson (1982). Free phages were isolated from lysogens by inoculating pyrophosphate-washed spores of the lysogens into soft agar overlays seeded with $S$. lividans 1326 spores. The phages released from $S$. lividans TK64: : KC591 lysogens were characterized by picking plaques (16 per plate) to soft agar overlays seeded with $S$. lividans 1326 spores, incubating these overnight, treating them with chloroform to kill the remaining 1326 growth and replicating them to R2YE plates seeded with S. lividans TK64 spores. After incubation the resulting well-sporulated lawns were replicated to supplemented MM plates containing either thiostrepton or viomycin to select for resistant transductants.

Culture, transformation and colony hybridization of $E$. coli were carried out as described by Maniatis $e t$ al. (1982).

In vitro manipulation of DNA. Plasmid, phage and chromosomal DNAs were isolated as described by Hopwood et al. (1985). All genetic characteristics (particularly those of the unstable donor types) were tested before chromosomal DNA isolation. Endonucleases and DNA ligase were used as recommended by the suppliers. Electro-elution of DNA fragments from agarose gels was as described by Maniatis et al. (1982). DNA-DNA hybridizations (including the pBR327 hybridizing standard) were as described by Lydiate et al. (1986). 
Table 1. Streptomyces strains

John Innes stock number
Description*

Reference $†$

S. coelicolor A3(2)

derivatives

1190

1889

1915

1956

1984

2106

2147

2293

2361

2612

A200

A317

A607

A608

A634

A700

DL30

DL31

DL32

DL33

DL34

DL35

DL140

DL142

DL177

J1501

M107

M130

M138

M145

S. lividans 66

derivatives

1326

DH97

DH102

DL1

DL3

DL4

DL5

DL73†

DL102

DL105

TK54

TK64

\author{
hisAl strAl uraAl $\left(\mathrm{SCP}^{-}{ }^{-} \mathrm{SCP} 2^{+}\right)$ \\ $\mathrm{pgl}$ mutant of A200 \\ pgl mutant of 1190 \\ cysB6 hisD3 strAl $\left(\mathrm{SCP1}^{-} \mathrm{SCP} 2^{+}\right)$ \\ 1956 containing SCP1'-cys $B$
}

phe $A$ I (SCP1 integrated to give stable cys $D$ donor)

pgl mutant of $\mathrm{A} 700$

cysB6 hisD3 strAl (bidirectional donor derived from SCPl'-cysB)

$\mathrm{pgl}$ mutant of 1956

argAl cysD18 proAl (NF, SCP2-)

ade-v10 pheAl strA5 (SCP1- $\left.\mathrm{SCP} 2^{+}\right)$

hisAl strAl uraAl (NF)

phe $A$ I (transient interaction of SCPI with the chromosome to give unstable

pabA donor)

pheAl (SCP1 integrated to give stable $p a b A$ donor)

$\operatorname{argAl}$ cys $A 24$ proAl strAl (NF-like donor)

argAI cysD18 proAl (SCP1- $\left.\mathrm{SCP} 2^{+}\right)$

J1501 : :KC591 (prophage integrated at secondary site C)

J1501 : :KC591 (prophage replaced mini-circle copy A)

J1501 : :KC591 (prophage replaced mini-circle copy A)

J1501 : : KC591 (prophage integrated at secondary site D)

J1501 : : KC591 (prophage integrated at secondary site D)

J1501 : : KC591 (prophage not integrated via mini-circle)

1190 mini-circle B : : KC590

1190 mini-circle A : : KC590

DL31 with additional $\mathrm{Arg}^{-}$and $\mathrm{Cys}^{-}$mutations

pgl mutant of M130

argAl cysD18 proAl (SCP1- SCP2*)

hisAl strAl uraAl $\left(\mathrm{SCP}^{-} \mathrm{SCP} 2^{-}\right)$

argAI cysD18 proAl $\left(\mathrm{SCP}^{+}{ }^{+} \mathrm{SCP} 2^{-}\right)$

'Wild-type' (SCP1- SCP2-)

A

B

B

C

C

D

C

B

B

A

A

E

E

E

F

G

G

G

G

G

G

G

G

G

$\mathrm{H}$

F

I

J

J

Wild-type (SLP2 ${ }^{+}$SLP3 $^{+}$)

TK64:: : pIJ983

TK64 : : pIJ983

TK64 : : KC591 (prophage integrated at secondary site A)

TK64 : :KC591 (prophage integrated at secondary site B)

TK64 : : KC591 (prophage integrated at preferred site)

TK64 : :KC591 (prophage integrated at preferred site)

TK 54 : : KC591 (prophage integrated at preferred site)

$\operatorname{Dog}^{\mathrm{R}} \mathrm{Vio}^{\mathrm{S}}$

TK64 : : KC591 (prophage integrated at preferred site)

$\mathrm{Sel}^{\mathrm{R}} \mathrm{Vio}^{\mathrm{S}}$

TK54::KC591 (prophage integrated at preferred site) $\mathrm{Se}^{\mathrm{R}} \mathrm{Vio}^{\mathrm{S}}$

his-2 leu-2 spc-1 (SLP2- SLP3-)

pro-2 str-6 (SLP2- SLP3-)

$\mathrm{L}$

$\mathrm{L}$

L

$\mathrm{L}$

G

G

G

$\mathbf{M}$

* Symbols for genetic markers as in Hopwood et al. (1985). Resistance phenotypes: DogR , 2-deoxyglucose resistant; Sel $^{\mathrm{R}}$, selenate resistant; $\mathrm{Vio}^{\mathrm{S}}$, viomycin sensitive.

$\dagger$ A, Vivian \& Hopwood (1970); B, H. M. Kieser, unpublished; C, Hopwood \& Wright (1976a); D, Hopwood \& Wright (1976b); E, Vivian \& Hopwood (1973); F, Bibb et al. (1977); G, this work; H, Chater et al. (1982); I, Bibb et al. (1981); J, M. J. Bibb, unpublished; K, Lomovskaya et al. (1972); L, Lydiate et al. (1986); M, Hopwood et al. (1983).

$\ddagger$ These strains independently suffered large deletions, each of which removed the left prophage/chromosome junction (Figs 5 and 6). 
Table 2. Plasmids and phages

Plasmids

Description*

Sourcet

pBR327 E. coli cloning vector

pIJ680

pIJ702

pIJ950

pIJ952

pIJ954

pIJ955

pIJ956

pIJ957

pIJ958

pIJ959

pIJ961

pIJ962

pIJ963

pIJ965

pIJ966

pIJ981

pIJ982

A Streptomyces plasmid cloning vector

A Streptomyces plasmid carrying the $t s r$ gene

pBR327 : free mini-circle

pBR327 : mini-circle copy A

pIJ2920:mini-circle copy A (left end)

As pIJ954 but with opposite insert orientation

pIJ2920:1.45 kb Sst I fragment of DJ1

As pIJ956 but with opposite insert orientation

pIJ2920:mini-circle copy A (right end)

pIJ2920:4.5 kb BglII-Sst I fragment of DJ2

pIJ2925 : mini-circle copy A (right end)

pIJ2925 : mini-circle copy B (right end)

pIJ2922:1.75 kb PstI-Bam HI hyg gene fragment of pIJ2349

pSAE : mini-circle copy A

pSAE : mini-circle copy B

pIJ2926: $S$. coelicolor sel/cys cluster

pIJ963 with DNA naturally flanking the left end of mini-circle copy A

inserted adjacent to the hyg gene

pIJ983

pIJ982 with DNA naturally flanking the right end of mini-circle copy $A$

inserted adjacent to the other end of the hyg gene

plJ987

pIJ 2220

pIJ2349

pIJ2920

pIJ 2922

pIJ2925

pIJ2926

PSAE

As pIJ962 but with opposite insert orientation

pSAE : mini-circle copy A

pIJ680: hyg gene of $S$. hygroscopicus

pUC18 derivative with modified poly-linker

pUC18 derivative with modified poly-linker

pUC18 derivative with modified poly-linker

pUC18 derivative with modified poly-linker

pUC18

E. coli cosmid cloning vector

$E$. coli cloning vector

A

B

C

D

E

E

E

F

$\mathbf{F}$

E

F

E

E

G

G

G

G

$\mathbf{H}$

E

I

J

K

K

K

$\mathbf{K}$

L

M

$\phi$ C31-derived phages

DJ1

Released from strain DL4, transduced $S$. lividans to Thio $^{\mathrm{R}}$ alone at a moderate efficiency

DJ2

Released from strain DL4, transduced S. lividans to $\mathrm{Vio}^{\mathrm{R}}$ alone at a low efficiency

DJ3

Released from strain DL5, transduced $S$. lividans to Thio ${ }^{\mathrm{R}}$ alone at a moderate efficiency

DJ4

Released from strain DL5, transduced $S$. lividans to $\mathrm{Vio}^{\mathrm{R}}$ alone at a low efficiency

DJ5

Released from strain DLl, transduced $S$. lividans to $\mathrm{Vio}^{\mathrm{R}}$ alone at a low efficiency

$\phi \mathrm{C} 31$ att $P^{+} c^{+} \Delta 23:: \mathrm{pBR} 322 \Delta \mathrm{W} 12:$ : vph

$\mathrm{KC} 300$

KC515

$\phi \mathrm{C} 31$ att $P^{-} c^{+} \Delta \mathrm{W} 17:: \mathrm{pBR} 322:: v p h:: t s r$

KC590

KC515 carrying the internal $1.82 \mathrm{~kb}$ SstI-BclI fragment of the mini-circle ( $v$ ph gene partially deleted)

KC515 carrying the entire free mini-circle linearized at the $B c l$ site

KC591

* hyg, gene conferring hygromycin resistance; $\mathrm{Thio}^{\mathrm{R}}$, thiostrepton resistance; $\mathrm{Vio}^{\mathrm{R}}$, viomycin resistance; $t s r$, gene conferring Thio ${ }^{\mathrm{R}}$; $v$ h, gene conferring $\mathrm{Vio}^{\mathrm{R}}$.

† A, Soberon et al. (1980); B, Hopwood et al. (1985); C, Katz et al. (1982); D, Lydiate et al. (1986); E, Fig. 3; F, Fig. 6; G, this work; H, Fig. 7; 1, Smith \& Chater (1988); J, F. Malpartida, personal communication; K, G. R. Janssen, personal communication; L, Grosveld et al. (1982); M, Yanisch-Perron et al. (1985); N, Chater et al. (1982); O, Rodicio et al. (1985); P, Lydiate et al. (1988).

\section{RESULTS}

Genetic mapping of the integrated mini-circle copies of $S$. coelicolor

Direct genetic mapping of the integrated mini-circle copies was not possible because they do not confer any known phenotype on their $S$. coelicolor host. Therefore, KC590 prophages (att $P^{-} t s r$ derivatives of phage $\phi \mathrm{C} 31$ containing an internal segment of the mini-circle) were 


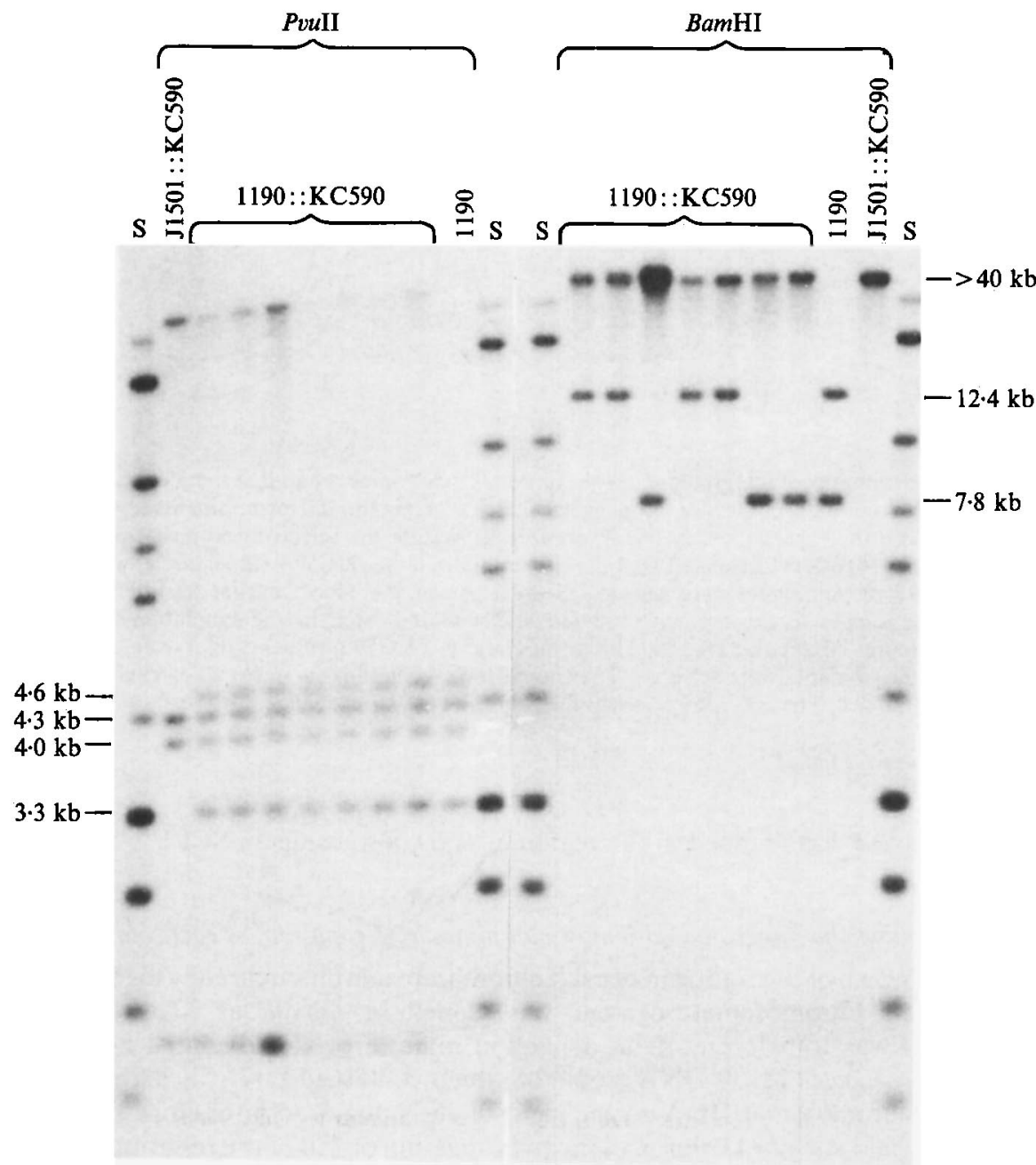

Fig. 1. Southern hybridization of a ${ }^{32} \mathrm{P}$-labelled pIJ950 (pBR322:free mini-circle) probe to DNA samples as indicated. S, pBR327 hybridizing standard (Lydiate et al., 1986) with fragments 27.4, 17.6, $10 \cdot 1,7 \cdot 6,6 \cdot 3,4 \cdot 4,3 \cdot 3,2 \cdot 6,1 \cdot 85$ and $1.4 \mathrm{~kb}$ in size. The absence of either the $7 \cdot 8 \mathrm{~kb}$ (mini-circle copy A) or the $12.4 \mathrm{~kb}$ (mini-circle copy B) BamHI fragment from the $S$. coelicolor $1190:: \mathrm{KC} 590$ lysogens demonstrated prophage integration into one or other of these fragments. (The KC 590 prophages have no BamHI sites and yield a $40 \mathrm{~kb} \mathrm{BamHI}$ fragment.) The retention of the four normal mini-circlehomologous PvuII bands (4.6, 4.3, 4.0 and $3.3 \mathrm{~kb}$ in size) by all seven $1190::$ KC590 lysogens demonstrated that in each case the normal mini-circle/chromosome junctions had been maintained.

integrated into the two linear mini-circle copies of $S$. coelicolor 1190 by homologous recombination (Lydiate et al., 1986, and Fig. 1) and their thiostrepton resistance gene (tsr) was used to map the mini-circle copies just as the viomycin resistance gene $(v p h)$ of $\mathrm{KC} 407$ prophages was used to map the IS110 copies of $S$. coelicolor (Chater et al., 1985).

Mini-circle copy A was mapped close to $\arg A$ using a cross involving the SCP1 ${ }^{\mathrm{NF}}$ fertility factor (Fig. 2a). Consideration of the allele frequencies placed $t s r$ either between pro $A$ and $u r a A$ ( $\operatorname{arc} 6)$ or close to $\arg A$. Since segregation of $t s r$ was essentially independent of the segregation of proA or of uraA, but strongly dependent on the segregation of $\arg A$ (Fig. $2 a$ ), the latter position was indicated. This position was confirmed when mini-circle copy A and the gyloperon (which also maps close to $\arg A$ : Seno et al., 1984) were found to be separated by only $20 \mathrm{~kb}$ in the cloned S. coelicolor DNA of pIJ2220 (see below). 
(a)

$$
\begin{array}{crr} 
& t s r & + \\
\arg A & 1 & 38 \\
+ & 58 & 3 \\
\text { uraA } & 47 & 32 \\
+ & 12 & 9 \\
\text { proA } & 30 & 25 \\
+ & 29 & 16
\end{array}
$$

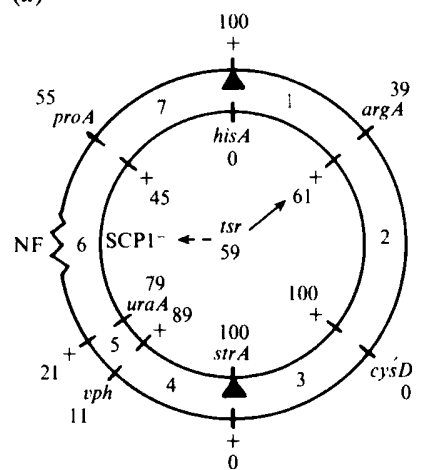

(b)

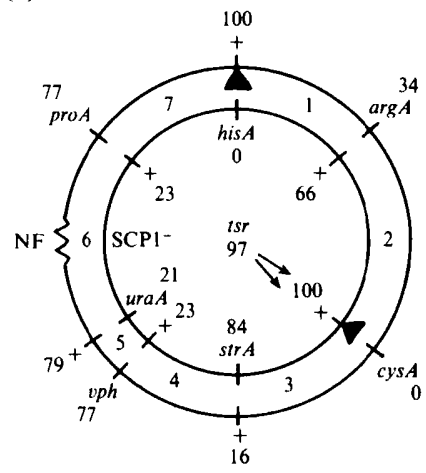

Fig. 2. Genetic mapping of integrated $S$. coelicolor mini-circle copies A and B. Triangles mark selected alleles. Numbers round the circles are frequencies of alleles among the 100 recombinants scored and the numbers between the circles identify the seven arcs separating the selected and unselected loci. (a) Strains 2612(KC300) (outer circle) and DL142 (1190 mini-circle A : :KC590) (inner circle) were crossed and his $A^{+}$strAl recombinants were selected. Segregation of the Thio ${ }^{\mathrm{R}}$ marker (tsr) of the KC590 prophage with respect to the arg, ura and pro alleles is indicated in the tabulation. (b) Strains 2612(KC300) (outer circle) and DL140 (1190 mini-circle B : :KC590) (inner circle) were crossed and his $A^{+}$cys $D^{+}$recombinants were selected. The three Thios recombinants in $(b)$ all carried the $\arg A l$, proAl and $v p h$ alleles. The $v p h$ gene was supplied by the KC300 prophage.

Mini-circle copy $\mathrm{B}$ was mapped in the region of $c y s D$, also using an $\mathrm{SCP} 1^{\mathrm{NF}} \times \mathrm{SCP}^{-}$cross $^{-}$ (Fig. 2b).

\section{Cloning the integrated, chromosomal mini-circle copies of $S$. coelicolor}

Approximately $2 \mathrm{~kb}$ of the right end of each chromosomal mini-circle copy together with $6 \mathrm{~kb}$ of each adjoining chromosomal segment was cloned in $E$. coli as follows. E. coli $\left(\mathrm{F}^{-}\right.$ lac Z $\Delta \mathrm{M} 15 \mathrm{rec} A$ ) was transformed with a ligation mixture of electro-eluted $8.0-8.6 \mathrm{~kb} S p h \mathrm{I}$ fragments of $S$. coelicolor M130 DNA (some of which contained DNA including most of the mini-circle and chromosomal DNA to the right of the integrated mini-circle copies: Fig. 3) inserted into the SphI site of pIJ2925. Colony hybridization of 240 of the resulting LacZ- clones (using the $1.8 \mathrm{~kb} \mathrm{BclI}-S s t \mathrm{I}$ internal mini-circle fragment as a probe) revealed 12 clones with homology to the mini-circle. Partial restriction mapping demonstrated that two of the clones contained mini-circle copy A with the insert in a single orientation (pIJ961: Fig. 3), six contained mini-circle copy B in one orientation (pIJ962) and four contained copy B in the opposite orientation (pIJ987).

Three cosmid clones each carrying $30-40 \mathrm{~kb}$ of $S$. coelicolor M138 DNA inserted into the pSAE vector and containing integrated mini-circle copies were isolated from a library of 500 cosmid clones (Smith \& Chater, 1988) probed with the $1.8 \mathrm{~kb} \mathrm{BclI-SstI}$ internal mini-circle fragment. One of these clones (pIJ2220) had previously been shown to contain the $S$. coelicolor gyl operon (Smith \& Chater, 1988). The $g y l$ operon was $20 \mathrm{~kb}$ to the left of mini-circle copy A in pIJ 2220 and the S. coelicolor DNA insert of pIJ 2220 ended $1.7 \mathrm{~kb}$ to the right of copy A (Fig. 3). The two other cosmid clones, pIJ965 and pIJ966, contained mini-circle copies A and B, respectively, but were not mapped in detail.

Mini-circle copy A flanked by $S$. coelicolor chromosomal sequences was subcloned as a $7.8 \mathrm{~kb}$ $B a m H I$ fragment from pIJ 2220 into the BamHI site of pBR327. Recombinant plasmids such as pIJ952 (Fig. 3), where the insert was orientated such that transcription from the vector tet promoter read into the right end of the insert, were structurally stable; plasmids with the insert in the opposite orientation suffered deletions in $E$. coli. The left mini-circle/chromosome junction together with $1.5 \mathrm{~kb}$ of flanking chromosomal DNA was subcloned as a $1.8 \mathrm{~kb} \mathrm{Bcl}$ ) fragment from pIJ952 into the BamHI site of pIJ2920 to form pIJ954 and pIJ955 (Fig. 3). 

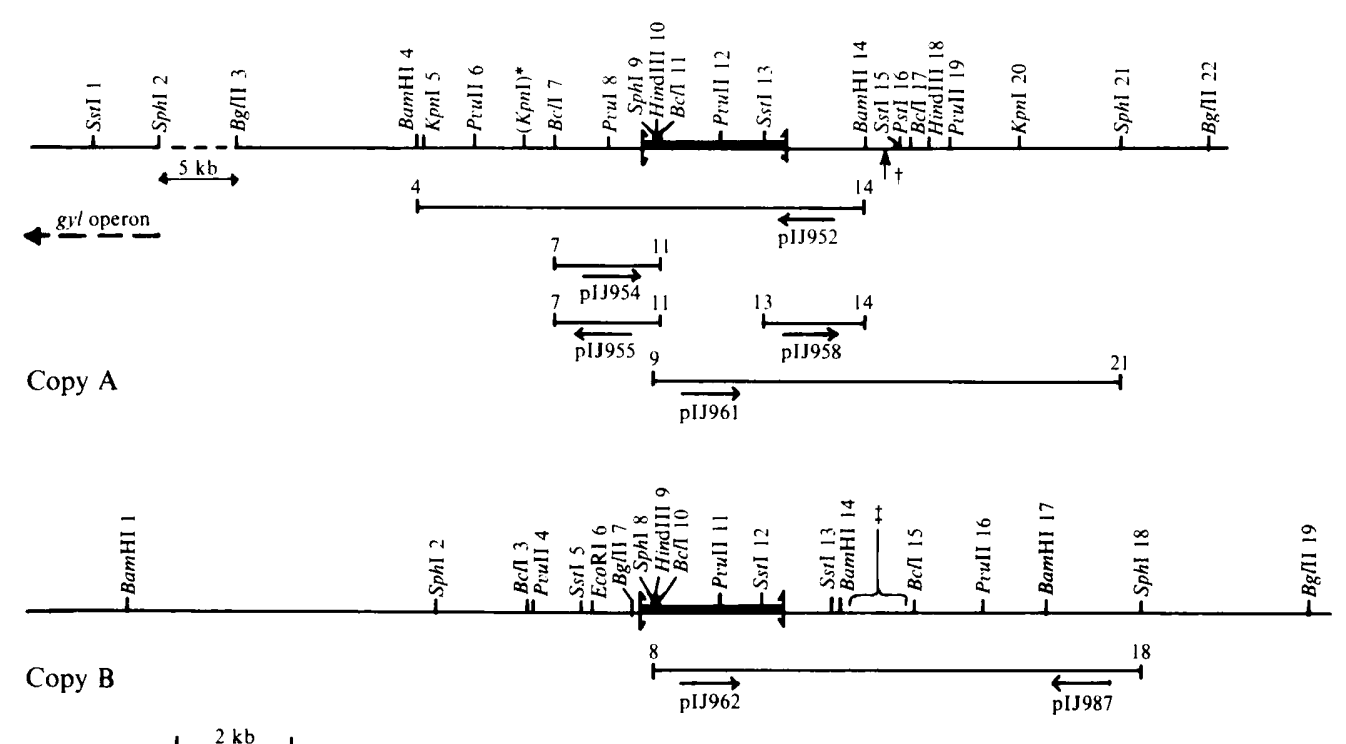

Fig. 3. Partial restriction maps of the two integrated mini-circle copies of the $S$. coelicolor chromosome: thick lines, mini-circle sequences; thin lines, flanking DNA. For most enzymes, only those cleavage sites closest to the mini-circle, in each of the four flanking regions, have been positioned. The extent of various cloned portions of $S$. coelicolor DNA is indicated by horizontal lines below the restriction maps. Arrows above plasmid numbers indicate the direction of transcription of the vector genes, lac $Z$ (pIJ2920 and pIJ2925) or tet (pBR327), with respect to the cloned inserts. *, The KpnI site in parentheses is not present in $S$. coelicolor but occurs in $S$. lividans (it was mapped in pIJ959 and confirmed by Southern hybridization analysis of $S$. lividans DNA using pIJ954 as probe). $\dagger$, The arrow indicates one end of the cloned $S$. coelicolor DNA of cosmid pIJ2220. $\ddagger$, The $0.97 \mathrm{~kb}$ insertion in $S$. coelicolor M145 occurred between the Bam HI and BclI sites flanking the right end of mini-circle copy B.

Similarly, the right mini-circle/chromosome junction was subcloned as a $1.75 \mathrm{~kb}$ BamHI-SstI fragment from pIJ952 into pIJ2920 by BamHI-SstI replacement to form pIJ958.

\section{Mini-circle copy $B$ and the pgl locus}

To investigate the possibility that the excision and reintegration of mini-circle copy $B$ was involved with the instability of the Pgl phenotype the DNA of four $\mathrm{pgl}$ mutants, together with that of their $\mathrm{pgl}^{+}$progenitors (1889 and A200; 1915 and $1190 ; 2147$ and A700;2361 and 1956) was digested with BamHI or with PvuII and subjected to Southern hybridization analysis using mini-circle DNA (pIJ950; Table 2) as a probe. All eight strains had normal $S$. coelicolor minicircle copy $\mathrm{A}$ and $\mathrm{B}$ bands, indicating that $\mathrm{Pgl}$ instability does not involve the mini-circle.

DNA of the same four $p g / / p g l^{+}$pairs, together with that of $S$. coelicolor J1501 and M130 and $S$. lividans 1326, was digested with Sst I and subjected to Southern hybridization analysis using pIJ962 (Fig. 3) as a probe. Bands corresponding to mini-circle copy B and the $6 \mathrm{~kb}$ of flanking chromosomal DNA present in pIJ962 were absent from strain J1501 but present in all other $S$. coelicolor strains tested. This indicated that a deletion extending outside mini-circle copy B (at least to the right) had occurred in strain J1501 and that the mini-circle copy had not excised precisely. The $S$. lividans 1326 DNA contained fragments homologous to the $S$. coelicolor chromosomal sequences flanking the right end of mini-circle copy $\mathbf{B}$; however, these sequences did not function as a preferred site for mini-circle integration in S. lividans (Lydiate et al., 1986).

The $S$. coelicolor mini-circle copies are unchanged in highly fertile donor strains

To investigate whether the mini-circle had promoted any of the known SCP1 integrations responsible for the creation of donor strains (Hopwood et al., 1984), the DNA of these strains 


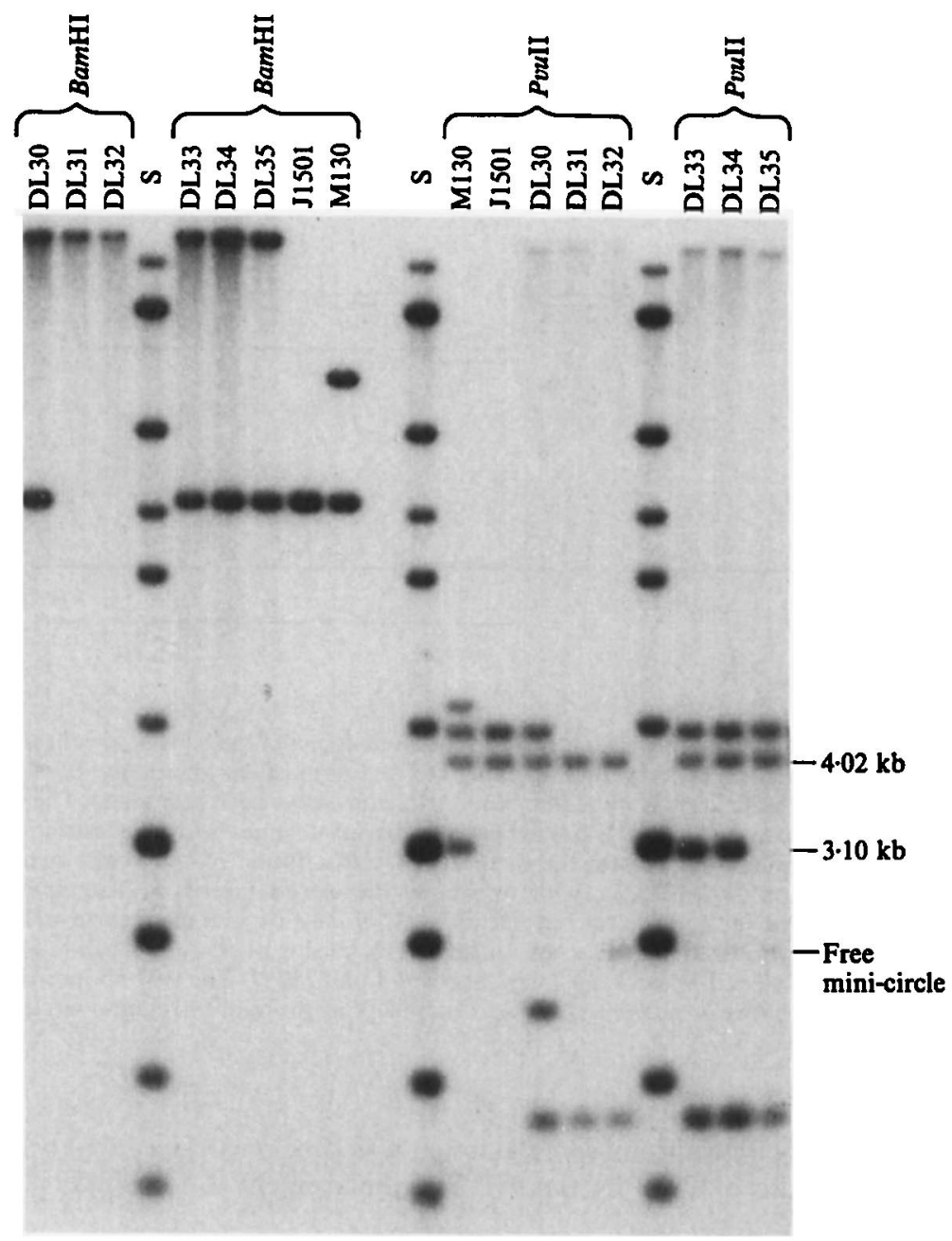

Fig. 4. Southern hybridization of a ${ }^{32} \mathrm{P}$-labelled pIJ950 probe to DNA samples as indicated. S, pBR327 hybridizing standard (see Fig. 1). The elevated copy numbers of the KC591 prophages compared to mini-circle copy A in strains DL33 and DL34 was indicated by the high intensity of prophage bands (e.g. $3 \cdot 10 \mathrm{~kb}$ PvuII) when compared to the analogous mini-circle copy A bands (e.g. $4.02 \mathrm{~kb} P v u \mathrm{II}$ ).

(1984, 2106, 2293, A317, A607, A608 and A634: Table 1) together with that of the progenitor strains was digested with BamHI or PvuII and subjected to Southern hybridization analysis using pIJ950 as a probe. Neither mini-circle copy was altered in any of the donor strains tested.

The DNA of $S$. coelicolor M145 (used as a control in the above experiment) showed an altered mini-circle copy B hybridization pattern. Similar Southern analysis of M145 DNA digested with $B c l \mathrm{I}, P s t \mathrm{I}, S p h \mathrm{I}$ or SstI revealed that this strain carried a $0.97 \mathrm{~kb}$ DNA insert (with at least one Pst I site) to the right of mini-circle copy B (Fig. 3). This insert had no homology to the $2.6 \mathrm{~kb}$ mini-circle and differed from IS 110 , which is $1.6 \mathrm{~kb}$ in length (Chater et al., 1985), and the unnamed $1 \mathrm{~kb}$ element of Kendall \& Cullum (1986), which had no PstI site.

Integration of phage KC591 into S. coelicolor J1501 directed by the mini-circle

The mini-circle insert of phage KC591 actively integrates this phage into the $S$. lividans chromosome to yield $\mathrm{Thio}^{\mathrm{R}}$ lysogens (Lydiate et al., 1986). S. coelicolor J1501, which carries only mini-circle copy A (at the site on the $S$. coelicolor chromosome homologous to the preferred 


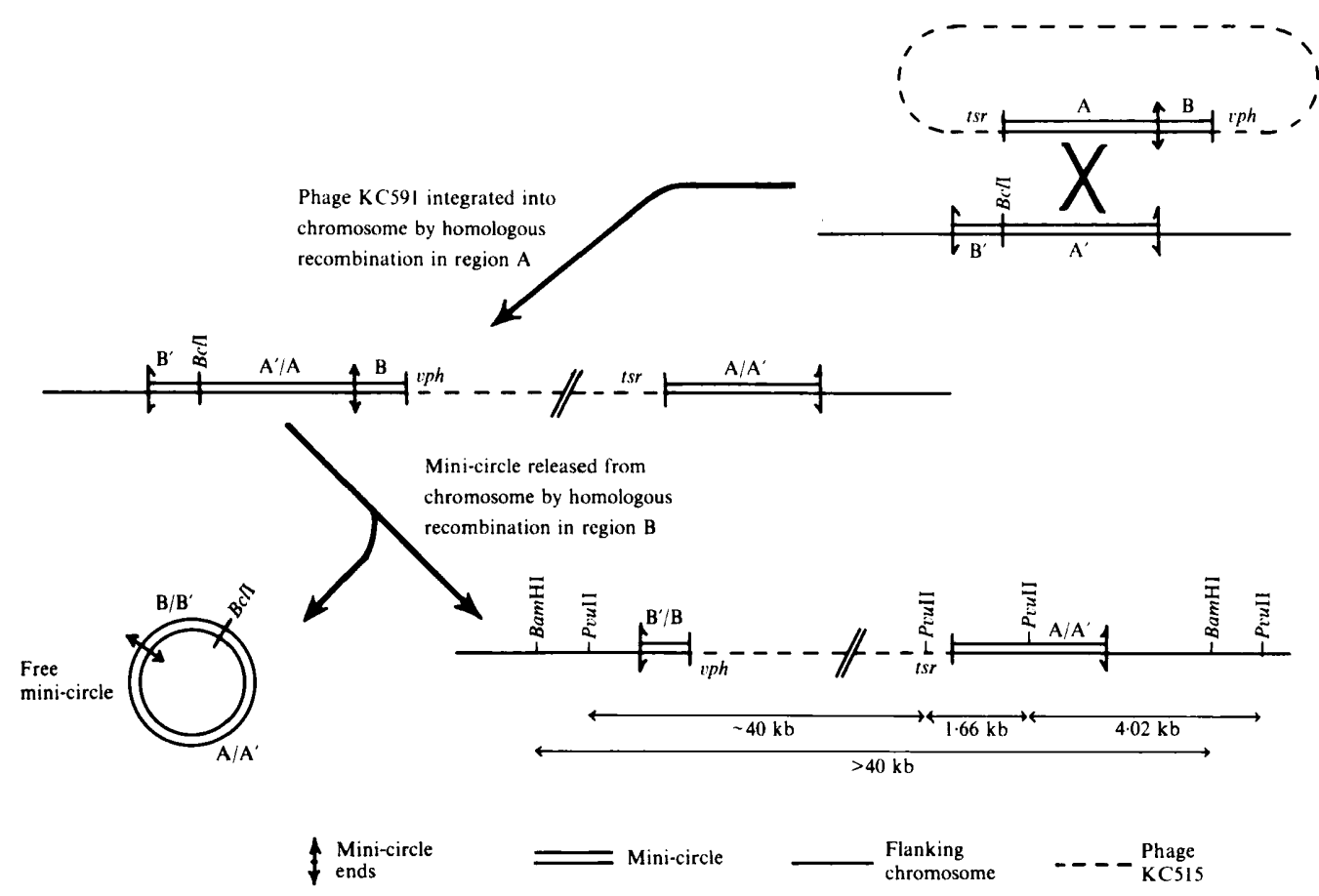

Fig. 5. Two rounds of homologous recombination between mini-circle sequences carried by $\mathrm{KC} 591$ and those present in the $S$. coelicolor J1501 genome could account for the replacement of mini-circle sequence A by KC591 prophages in strains DL31 and DL32.

integration site for KC591 in S. lividans), was infected with KC591 and the DNA of six of the resulting Thio ${ }^{\mathrm{R}}$ transductants (DL30 to DL35) was digested with BamHI or PvuII and subjected to Southern hybridization analysis using pIJ950 as a probe (Fig. 4).

In two of the J1501::KC591 lysogens (DL31 and DL32) KC591 had replaced mini-circle copy A. Because the mini-circle sequence in KC591 (linearized at the BclI site) is a circular permutation of mini-circle copy $A$ (which is linearized at the mini-circle integration point) this replacement is most easily explained by two successive homologous recombination events (Fig. 5). No free mini-circle DNA was detected in strain DL31 (Fig. 4), and the $2.6 \mathrm{~kb}$ mini-circlehomologous PvuII fragment detected in strain DL32 might not have originated from free minicircles but rather from an unresolved Campbell structure analogous to that depicted in Fig. 5 but in which phage KC591 had integrated via homologous recombination between the short (B/B') regions of homology.

Strains DL30, DL33 and DL34 contained KC591 prophages linearized at (or near) their minicircle integration points and inserted into the $S$. coelicolor genome at a point removed from minicircle copy A. The KC591 prophages of DL33 and DL34, which might have the same integration point in the $S$. coelicolor genome, appeared to have a copy number approximately twice that of the chromosomal mini-circle copy A (Fig. 4). The integration of the KC591 prophages of strains DL33 and DL34 into a specific site on a plasmid with a copy number of two per genome would explain these observations. Conceivably the plasmid in question was SLP4 (Hopwood et al., 1983).

The sixth J1501 : :KC591 lysogen (DL35) exhibited the banding pattern expected of a strain carrying a circular KC591 prophage (Fig. 4). This banding pattern could also be explained by a linear, integrated prophage resulting from the lysogenizing KC591 phage having acquired a copy of an insertion sequence (such as IS 110 ) in the $\phi \mathrm{C} 31$ sequences close to the $t s r$ gene and having subsequently become integrated into the host chromosome by homologous recombinations with a chromosomal copy of the same element. 
Attempt to isolate selenate-resistant $\left(\mathrm{Sel}^{R}\right)$ or 2-deoxyglucose-resistant $\left(\operatorname{Dog}^{R}\right)$ mutants generated by KC591 integration in $S$. lividans

Replication of approximately 40000 colonies of independent KC591 lysogens of $S$. lividans TK64 and TK54 to media selecting Sel ${ }^{R}$ mutants (mutated in genes involved in the early stages of sulphate reduction: Lydiate et al., 1988) or Dog ${ }^{\mathrm{R}}$ mutants (produced by glucose kinase mutation: Ikeda et al., 1984) yielded 10 and 11 isolates, respectively. Southern hybridization analysis demonstrated that each isolate, except the $\mathrm{Sel}^{\mathrm{R}}$ mutant DL101, contained a single KC591 copy integrated at the $S$. lividans preferred site. Probing DNA of $S$. lividans DL101 with the cloned sel/cys gene cluster (pIJ981) demonstrated that the KC591 prophage of this strain was not present in or near these genes. Thus no KC591-induced, insertional mutations were obtained.

Three of the above isolates (DL73, DL102 and DL105) had not been transduced to Vio ${ }^{\mathrm{R}}$ by KC591, whereas all other isolates were $\mathrm{Vio}^{\mathrm{R}}$ as well as $\mathrm{Thio}^{\mathrm{R}}$. The Southern hybridization analysis of these strains, together with the direct analysis of prophage Sst II bands (as in Fisher $e t$ al., 1987), revealed that all three strains had suffered large deletions which removed considerable portions of the KC591 prophages and chromosomal DNA around the left (vph) prophage/chromosome junction.

\section{Excision of the resident prophages from S. lividans TK64::KC591 and S. coelicolor J1501 : : KC591 lysogens}

The S. lividans TK64 lysogens DL4 and DL5 (in which the prophages were integrated at the preferred site) and DL1 and DL3 (in which the prophages were integrated at two different secondary sites) all released free phages at similar frequencies (approximately 0.01 plaques per lysogen spore). The biological properties of 32 newly-excised phages from each lysogen were studied. All these released phages differed from $\mathrm{KC} 591$, which transduced $S$. lividans to Thio ${ }^{\mathrm{R}}$ and $\mathrm{Vio}^{\mathrm{R}}$ at high frequency. Some $17 \%$ of the new phages transduced $S$. lividans to both $\mathrm{Thio}^{\mathrm{R}}$ and $\mathrm{Vio}^{\mathrm{R}}$ at moderate to low frequencies, $25 \%$ transduced it only to $\mathrm{Thio}^{\mathrm{R}}$ at a moderate frequency and $5 \%$ transduced it only to $\mathrm{Vio}^{\mathrm{R}}$ at a low frequency. The remaining phages were unable to transduce $S$. lividans to either $\mathrm{Thio}^{\mathrm{R}}$ or $\mathrm{Vio}^{\mathrm{R}}$ although the majority were able to transduce $S$. coelicolor to $\mathrm{Thio}^{\mathrm{R}}$ or to $\mathrm{Thio}^{\mathrm{R}}$ and $\mathrm{Vio}^{\mathrm{R}}$, presumably integrating into the $S$. coelicolor chromosome via recombination between shared mini-circle homology. All four of the initial lysogens released phages of the different kinds.

It was expected that phages transducing $S$. lividans to Thio $^{\mathrm{R}}$ alone had lost the $v p h$ gene at the left end of KC591 (see the KC591 prophage in Fig. 5), while those transducing S. lividans to Vio ${ }^{\mathrm{R}}$ alone had lost the tsr gene at the right end of KC591. The DNA of four phages (DJ1, DJ2, DJ3 and DJ4: Table 2) was subjected to restriction mapping and Southern hybridization analysis using probes (Fig. 3) specific for the left end (pIJ954) or right end (pIJ958) of mini-circle copy A; the results are summarized in Fig. 6. To assist in the localization of the points of illegitimate recombination which gave rise to phages DJ1 and DJ2 the $1.45 \mathrm{~kb} S s t$ I fragment of the former was cloned into the Sst I site of pIJ2920 to form pIJ956 and pIJ957 (Fig. 6) and the $4.5 \mathrm{~kb} \mathrm{BglII}-$ Sst I fragment of the latter was cloned into $\mathrm{pIJ} 2920$ by BamHI-Sst I replacement to form pIJ959 (Fig. 6).

As expected, the $V i^{R}$ transducing phages DJ2 and DJ4 had lost all the mini-circle sequences from the right end of the KC591 prophage together with much of the tsr gene and had acquired segments of $S$. lividans chromosomal DNA flanking the left end of the KC591 prophage (3.3 kt and $2.0 \mathrm{~kb}$ in length, respectively). Contrary to expectation, the Thio ${ }^{\mathrm{R}}$ transducing phage DJ 1 retained an intact $v p h$ gene and carried $S$. lividans chromosomal sequences from the left end of the KC591 prophage. Since the vph structural gene of KC591 lacks its promoter (Bibb et al.. 1985 ), the failure of DJ1 prophages to confer $V{ }^{R}$ on the majority of their $S$. lividans lysogens probably indicates the absence of transcription into the $v p h$ structural gene from adjacen 1 chromosomal/mini-circle sequences in these lysogens.

Phages DJ2 and DJ4 probably integrated into the $S$. lividans chromosome by homologous recombination between shared chromosomal sequences, but the much more efficien 1 

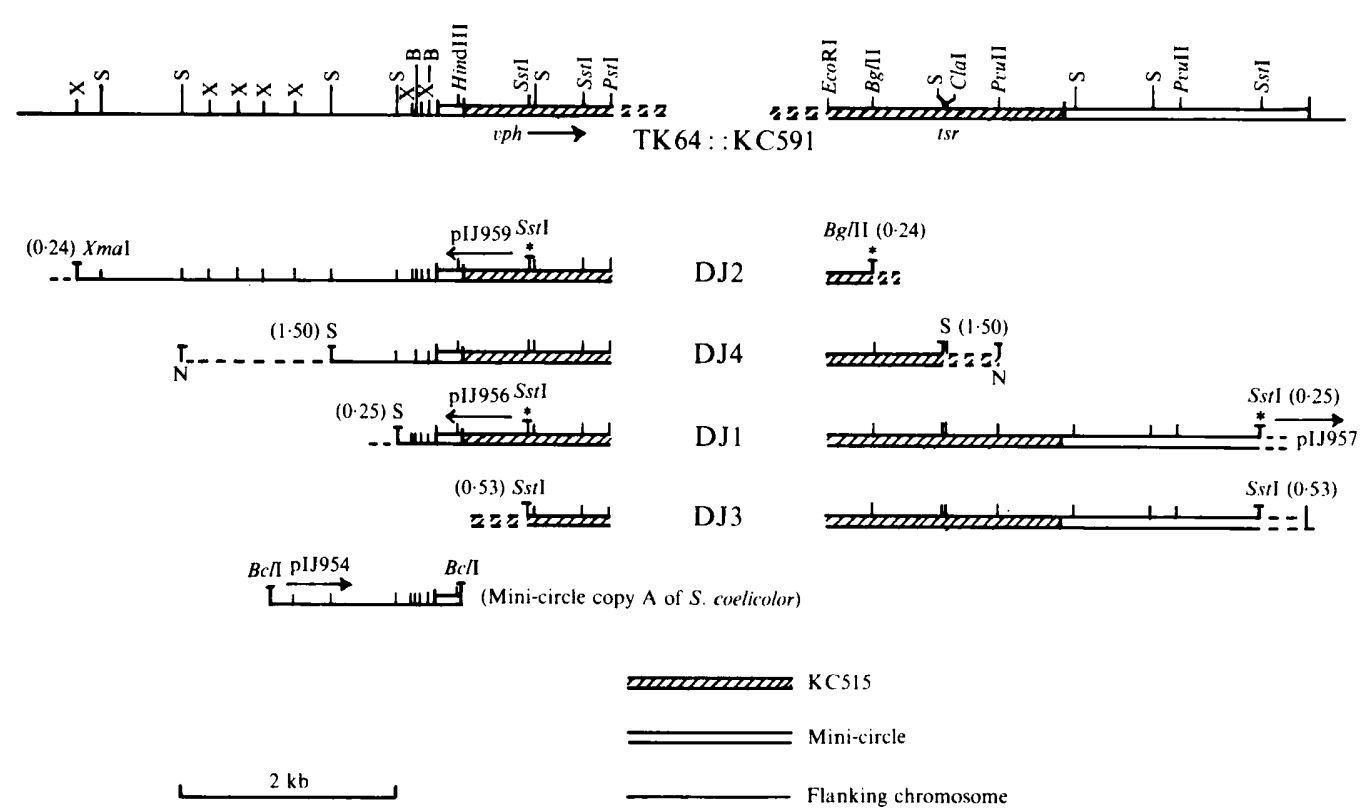

Fig. 6. Restriction maps of the ends of the KC591 prophages of S. lividans DL4 and DL5 lysogens (top line) and regions of the fused left and right prophage ends in the imprecisely excised phages DJ1, DJ2, DJ 3 and DJ4. Only BglII, ClaI, EcoRI, HindIII, Pst I, PvuII and Sst I sites in KC591 and XmaI (X) and the two $B g l$ I (B) sites closest to the left mini-circle/chromosome junction in the flanking chromosomal DNA are shown. All Sst II (S) sites are shown. The XmaI sites of DJ4 were not mapped. N, sites absent from $\mathrm{DJ} 4$; *, sites used in subcloning junction fragments; arrows indicate the direction of transcription of the vector lacZ gene in pIJ956, pIJ957 and pIJ959 and of the vph gene of phage KC591. Values in parentheses are the distances in $\mathbf{k b}$ between marked restriction sites.

integration of phages DJ1 and DJ3 (which carry considerably smaller segments of chromosomal DNA but retain most of the mini-circle sequences) is most easily explained by a residual minicircle-encoded integration activity, possibly able to act on the left or right minicircle/chromosome junctions of the KC591 prophage which were retained separately by DJ1 and DJ3, respectively. The failure of DJ1 prophages to express the $v p h$ gene suggests that they are not integrated at the $S$. lividans preferred site.

The physically less well characterized phages released from strains DL1 and DL3 had a similar range of structures to those derived from prophages integrated at the preferred site. For example, phage DJ5, which was released from strain DL1 and transduced $S$. lividans to Vio ${ }^{\mathrm{R}}$ alone and at a low frequency, had lost the right end of KC591 (to a point between the ClaI and $P v u I I$ sites of the $t s r$ gene) and had acquired $4.0-4.5 \mathrm{~kb}$ of $S$. lividans DNA flanking the left end of the KC591 prophage.

In an attempt to isolate $S$. lividans TK64 : : KC591 and $S$. coelicolor J1501 : : KC591 lysogens cured of their prophages, $S$. coelicolor DL31 and $S$. lividans DL1 and DL5 were grown in the absence of antibiotic selection and 1000 spores from the resulting lawn of each strain were inoculated onto complete medium (CM: Hopwood et al., 1985). After incubation, the resulting colonies were replicated to $\mathrm{MM}$ plates supplemented with only histidine, uracil and proline and containing thiostrepton and viomycin. All colonies were $\mathrm{Thio}^{\mathrm{R}}$ and $\mathrm{Vio}^{\mathrm{R}}$, indicating that none were spontaneously cured of the KC591 prophage.

The experiment was repeated (with strains DL5 and DL31) but the spores were first irradiated with UV to $1 \%$ survival in case this might stimulate excision. Nineteen of the 800 DL5 and 22 of the 2600 DL31 colonies tested failed to grow after replication. Ten and 12 of the isolated DL5 and DL31 derivatives, respectively, were weakly Vio ${ }^{R}$ (they grew on R2YE plates containing 
S. lividans chromosome

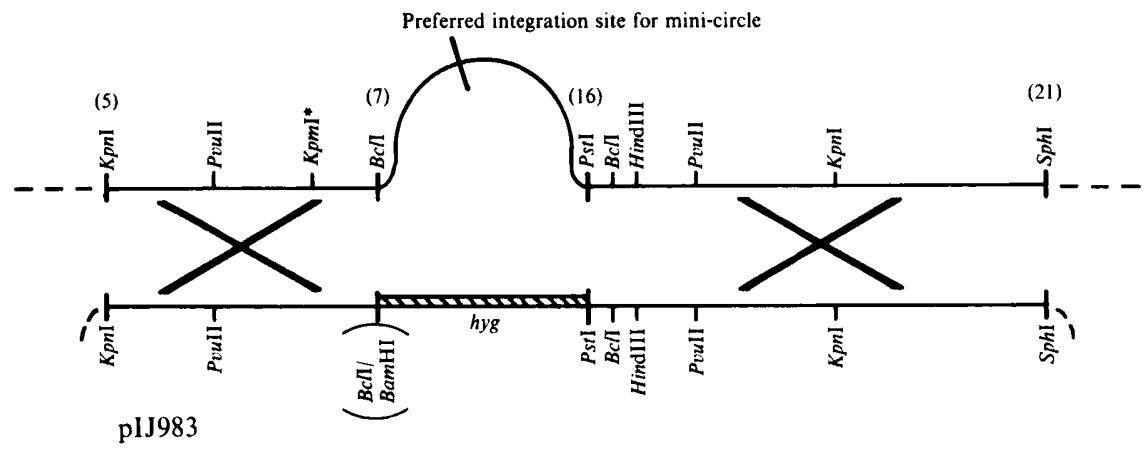

Fig. 7. Two homologous recombination events between the $S$. lividans chromosome and pIJ983, one in each of the two regions of homology, would result in the preferred mini-circle integration site of $S$. lividans being replaced with the hygromycin resistance gene of $S$. hygroscopicus.

$30 \mu \mathrm{g}$ viomycin $\mathrm{ml}^{-1}$ but not on $\mathrm{MM}$ plates containing $30 \mu \mathrm{g}$ viomycin $\mathrm{ml}^{-1}$ ) while four and three, respectively, were Vio (they failed to grow on R2YE plates containing $30 \mu \mathrm{g}$ viomycin $\mathrm{ml}^{-1}$ ). Five of the DL5 derivatives were Thios and six of the DL31 derivatives had single additional auxotrophic growth requirements for arginine, cystine, methionine or serine while one of the DL31 derivatives (DL177) had a double additional requirement for arginine and cystine. No isolate was completely cured of its KC591 prophage.

\section{Attempted replacement of the $S$. lividans TK64 preferred mini-circle integration site}

The replacement of the $S$. lividans TK64 preferred mini-circle integration site with a hygromycin resistance gene (hyg) flanked by cloned segments of chromosomal DNA to the left and to the right of $S$. coelicolor mini-circle sequence A was attempted using homologous recombination. The genomes of $S$. coelicolor and $S$. lividans are very similar and sufficient homology was present to allow recombination between the cloned $S$. coelicolor sequences and the $S$. lividans chromosome.

The replacement construct, pIJ983 (Fig. 7), was made by subcloning the $2.3 \mathrm{~kb} \mathrm{KpnI-BclI}$ fragment of the left flanking region in pIJ952 (Fig. 3, sites 5-7) into pIJ963 cut with BamHI + KpnI (pIJ963 carries the $1.75 \mathrm{~kb}$ PstI-Bam HI hyg gene fragment of pIJ2349 cloned into pIJ 2922 cut with Pst I + BamHI) to give pIJ982, followed by subcloning the $3.9 \mathrm{~kb}$ Pst ISphI fragment of the right flanking chromosomal region in pIJ961 (Fig. 3, sites 16-21) into pIJ982 cut with Pst I + SphI.

Transformation of $S$. lividans TK64 with intact pIJ983 yielded $10^{3}$ hygromycin-resistant transformants per $\mu \mathrm{g}$ of DNA and all the transformants analysed by Southern hybridization were found to contain pIJ983 integrated into the $S$. lividans chromosome via single homologous recombination events involving one or other of the regions of homology between pIJ 983 and the $S$. lividans chromosome. pIJ702 gave a control frequency of $10^{8}$ transformants per $\mu \mathrm{g}$ of DNA. Replacement of the preferred integration site with the hyg gene of pIJ983 would require two recombination events, one in each of the two homologous segments (Fig. 7).

Two of the $S$. lividans TK64::pIJ983 transformants, DH102, in which the plasmid had integrated via the left segment of homology, and DH97, in which the integration had occurred in the right segment of homology, were studied further. In both strains a second recombination event, between the direct repeats of left and right flanking sequences (present as a result of pIJ983 integration), would either excise the plasmid from the chromosome or delete the preferred integration site. Both events were screened for using colony hybridizations. After two rounds of sporulation on non-selective medium about $1 \%$ of colonies of both strains were shown to have lost the hyg gene by colony hybridization using a $h y g$-specific probe (the $P_{s t} \mathrm{I}-$ BamHI fragment of pIJ2349). A similar frequency was revealed by screening for loss of hygromycin 
resistance. However, screening 2000 colonies derived from each strain with a probe specific for the preferred site revealed no colonies that had lost the $3.4 \mathrm{~kb}$ region containing the preferred mini-circle integration site of $S$. lividans.

\section{DISCUSSION}

The two integrated mini-circle copies of $S$. coelicolor A3(2) were located on the $S$. coelicolor linkage map and were therefore shown to be chromosomal. Mini-circle copy A mapped close to the $\arg A$ locus and was positioned $20 \mathrm{~kb}$ upstream of the $g y l$ operon on the cloned $S$. coelicolor DNA of pIJ2220. Mini-circle copy B mapped close to the cysD locus and was included in a large fragment of chromosomal DNA deleted from strain J1501. This deletion might have been the cause of the $p g l$ mutation of strain J1501 ( $p g l$ also maps close to the cysD locus) and it is possible that the chromosomal DNA flanking mini-circle copy B and present on plasmids pIJ962 and pIJ966 will be useful as a molecular probe for the cloning of the $p g l$ locus. However, the analysis of a further four $p g l$ mutants demonstrated that changes in mini-circle copy B are not obligatorily correlated with changes in the Pgl phenotype.

A $0.97 \mathrm{~kb}$ insert was discovered in the chromosomal DNA flanking mini-circle copy B of strain M145. This insert is probably an example of a previously unidentified insertion sequence present in the $S$. coelicolor genome.

The KC591 prophages integrated by the mini-circle into the chromosomes of $S$. coelicolor DL31 and $S$. lividans DL1 and DL5 were stably inherited and structurally stable: they were not lost or rearranged in any of 3000 lysogen colonies tested. UV-irradiation appeared to disturb the KC591 prophages but it is not yet clear whether this UV-induced behaviour is due to mini-circle activation, to activation of the phage $\phi \mathrm{C} 31$ genes of the KC591 prophage, or simply to mutations in the host.

The deletions of the left end of the KC591 prophages together with flanking chromosomal DNA in strains DL73, DL102 and DL105 are analogous to the deletions associated with prophages of KC571 and KC572 derivatives (Fisher et al., 1987) and prophages of pPOD9 (Malpartida et al., 1987). An inadvertent selection for prophages unable to support the growth of spontaneously arising defective virulent derivatives of phage $\phi \mathrm{C} 31$ might account for the isolation of these deleted strains.

There is no evidence for the precise excision of integrated mini-circles: precise excision of KC591 has never been observed. Free phages were easily obtained from $S$. lividans : :KC591 lysogens but, while many of these carried large $(>3 \mathrm{~kb}$ ) lengths of the chromosomal sequences flanking the prophage, none $(<0 \cdot 1 \%)$ exhibited the behaviour of the original KC591 phage. The large insert of $\phi \mathrm{C} 31$ sequences in the $B c / \mathrm{I}$ site of the mini-circle in phage KC591 might have disrupted a function involved in mini-circle excision. The uninterrupted mini-circle copy A of J1501 lysogens DL30 and DL33 might provide trans-acting functions to allow the precise excision of their KC591 prophages, yielding free phages identical to KC591 and perhaps leading to strains cured of the phage. The cloning of mini-circle copy A in pIJ952 will allow the construction of a linear mini-circle copy marked with the $t s r$ gene and the subsequent testing of its ability to excise and reintegrate when introduced into $S$. lividans.

An effective transposon mutagen for the genus Streptomyces would be very useful. One candidate for such a mutagen is the $S$. fradiae transposable element Tn4556 (Chung, 1987). Phage KC591 is a particularly attractive potential mutagen because the imprecise excision of inserted KC591 prophages would allow the direct, in vivo cloning of any disrupted genes. However, KC591 was ineffective when used as a mutagen in S. lividans. This might have been due to the preponderance of insertions into the $S$. lividans preferred site $(95-98 \%$ of all TK64 : : KC591 lysogens carried KC591 at the preferred integration site: unpublished data) or to the existence of a limited number of secondary insertion sites precluding the disruption of the target glucose kinase and sulphate metabolism genes by insertion of KC591 prophages. KC591 might be a useful insertional mutagen in Streptomyces strains which do not have a preferred site for mini-circle integration.

The attempt to select derivatives of $S$. coelicolor : :KC591 and $S$. lividans : :KC591 lysogens 
cured of their KC591 prophages and deleted for the preferred mini-circle integration site was unsuccessful. It was hoped to remove the preferred integration site from $S$. lividans and minicircle copy A from $S$. coelicolor by homologous exchange with a clone carrying the flanking sequences from both sides of these structures, but the attempts in $S$. lividans proved unsuccessful, perhaps because the region containing the preferred integration site carried functions whose deletion was deleterious to the cell under the conditions used. Such functions would have to lie betweeen the mini-circle copy A integration site and PstI site 16 (Fig. 3) because sequences to the left of the mini-circle integration site were deleted from $S$. lividans strains DL73, DL102 and DL105. However, this experiment did demonstrate that efficient homologous recombination occurred between cloned $S$. coelicolor DNA and the homologous $S$. lividans sequences. Successful attempts to delete segments of Streptomyces genomes by homologous exchange have been reported. Eckhardt \& Smith (1987) successfully deleted the $S$. lividans $\beta$-galactosidase gene using segments of homology 0.7 and $1.2 \mathrm{~kb}$ in length cloned in $\phi \mathrm{C} 31$, and Anzai et al. (1988) introduced a mutated DNA segment into the step 5 bialaphos biosynthetic gene of $S$. hygroscopicus by putting the in vitro altered gene on a $S$. hygroscopicus plasmid, transforming the non-mutant strain and then making and regenerating protoplasts of the transformants. (No mutants were observed after transformation without subsequent protoplasting.)

The nucleotide sequence of the free mini-circle of $S$. coelicolor has been determined (D. J. Henderson, unpublished results), and clones described above (Fig. 3) will allow the nucleotide sequences of the mini-circle/chromosome junctions to be determined and allow the cloning of the unoccupied integration site. Knowing the sequences associated with mini-circle integration should establish the relatedness or otherwise of the mini-circle to other transposable elements such as the well-characterized transposable elements of $E$. coli (Calos \& Miller, 1980), the novel Tn 1545 element of Streptococcus pneumoniae (Caillaud \& Courvalin, 1987) and the integrating plasmids of Streptomyces and Nocardia (Bibb et al., 1981; Madon et al., 1987).

We thank Nigel Davis for his help with Streptomyces colony hybridizations.

\section{REFERENCES}

Anzai, H., Kumada, Y., Hara, O., Murakami, T., Itoh, R., Tamkano, E., Imia, S., Satoh, A. \& NAGAOKA, K. (1988). Replacement of Streptomyces hygroscopicus genomic segments with in vitro altered DNA sequences. Journal of Antibiotics 41, 226-233.

BibB, M. J., Freeman, R. F. \& HopwoOd, D. A. (1977). Physical and genetic characterisation of a second sex factor, SCP2, for S. coelicolor A3(2). Molecular and General Genetics 154, 155-166.

BIBB, M. J., WARD, J. M., KIESER, T., COHEN, S. N. \& HoPwOOD, D. A. (1981). Excision of chromosomal DNA sequences from $S$. coelicolor forms a novel family of plasmids detectable in S. lividans. Molecular and General Genetics 184, 230-240.

BibB, M. J., Bibb, M. J., WARD, J. M. \& CoheN, S. N. (1985). Nucleotide sequences encoding and promoting expression of three antibiotic resistance genes indigenous to Streptomyces. Molecular and General Genetics 199, 26-36.

Caillaud, F. \& Courvalin, P. (1987). Nucleotide sequence of the ends of the conjugative shuttle transposon Tn1545. Molecular and General Genetics 209, 110-115.

Calos, M. P. \& Miller, J. H. (1980). Transposable elements. Cell 20, 579-595.

Chater, K. F., Bruton, C. J., King, A. A. \& Suarez, J. E. (1982). The expression of Streptomyces and E. coli drug-resistance determinants cloned in the Streptomyces phage $\phi \mathrm{C} 31$. Gene 19, 21-32.
Chater, K. F., Bruton, C. J., Foster, S. G. \& Tobek, I. (1985). Physical and genetic analysis of IS 110 , a transposable element of $S$. coelicolor A3(2). Molecular and General Genetics 200, 235-239.

Chinenova, T. A., Mkrtumian, N. M. \& LomovSKAYA, N. D. (1982). Genetic characterisation of a new character of phage resistance in $S$. coelicolor A3(2). Genetika 18, 1945-1952.

ChUng, S.-T. (1987). Tn4556, a $6.8 \mathrm{~kb}$ transposable element of $S$. fradiae. Journal of Bacteriology 169 , 4436-4441.

DeONIER, R. C. \& HADLEY, R. G. (1980). IS2-IS2 and IS3-IS3 relative recombination frequencies in $F$ integration. Plasmid 3, 48-64.

ECKHARDT, T. \& SMITH, R. (1987). Use of a secreted $\beta$ galactosidase to study gene expression and secretion in Streptomyces. In Genetics of Industrial Microorganisms, Part B, pp. 17-27. Edited by M. Alacevic, D. Hranueli \& Z. Toman. Zagreb: Pliva.

Fisher, S. H., BRUton, C. J. \& ChATER, K. F. (1987). The glucose kinase gene of $S$. coelicolor and its use in selecting spontaneous deletions for desired regions of the genome. Molecular and General Genetics 206, 3544.

Grosveld, F. G., Lund, T., Murray, E. J., Mellor, A. L., DaHL, H. H. M. \& Flavell, R. A. (1982). The construction of cosmid libraries which can be used to transform eukaryotic cells. Nucleic Acids Research 10, 6715-6732. 
Guyer, M. S., Reed, R. R., Steitz, J. A. \& Low, K. B. (1980). Identification of a sex-factor-affinity site in $E$. coli as $\gamma \delta$. Cold Spring Harbor Symposia on Quantitative Biology 45, 135-140.

HodGson, D. A. (1982). Glucose repression of carbon source uptake and metabolism in Streptomyces coelicolor $\mathrm{A} 3(2)$ and its perturbation in mutants resistant to 2-deoxyglucose. Journal of General Microbiology 128, 2417-2430.

HoPWOOD, D. A. \& WRIGHT, H. M. (1976a). Genetic studies of SCPI-prime strains of Streptomyces coelicolor A3(2). Journal of General Microbiology 95, 107-120.

HoPWOOD, D. A. \& WRIGHT, H. M. (1976b). Interactions of the plasmid SCP1 with the chromosome of $S$. coelicolor A3(2). In The Second International Symposium on the Genetics of Industrial Microorganisms, pp. 607-619. Edited by K. D. Macdonald. London: Academic Press.

HoPWOOD, D. A., KiesER, T., Wright, H. M. \& BibB, M. J. (1983). Plasmids, recombination and chromosome mapping in Streptomyces lividans 66. Journal of General Microbiology 129, 2257-2269.

Hopwood, D. A., Lydiate, D. J., Malpartida, F. \& WRIGHT, H. M. (1984). Conjugative sex plasmids of Streptomyces. In Plasmids in Bacteria, pp. 615-634. Edited by D. Helinski, S. Cohen \& D. Clewell. New York: Plenum.

Hopwood, D. A., Bibb, M. J., Chater, K. F., Kieser, T., Bruton, C. J., KIESER, H. M., LydiaTE, D. J., Smith, C. P., Ward, J. M. \& SchrempF, H. (1985). Genetic Manipulation of Streptomyces: a Laboratory Manual. Norwich: John Innes Foundation.

IKeda, H., Seno, E. T., Bruton, C. J. \& Chater, K. F. (1984). Genetic mapping, cloning and physiological aspects of the glucose kinase gene of $S$. coelicolor. Molecular and General Genetics 196, 501-507.

KatZ, E., Thompson, C. J. \& Hopwood, D. A. (1982). Cloning and expression of the tyrosinase gene from Streptomyces antibioticus in Streptomyces lividans. Journal of General Microbiology 129, 2703-2714.

KeNDALl, K. \& Cullum, J. (1986). Identification of a DNA sequence associated with plasmid integration in S. coelicolor A3(2). Molecular and General Genetics 202, 240-245.

Lomovskaya, N. D., Mkrtumian, N. M., GostimSKayA, N. L. \& DaNilenko, V. N. (1972). Characterization of temperate actinophage $\phi \mathrm{C} 31$ isolated from S. coelicolor A3(2). Journal of Virology 9, 258262.

Lydiate, D. J., IKedA, H. \& Hopwood, D. A. (1986). A $2.6 \mathrm{~kb}$ DNA sequence of $S$. coelicolor A3(2) which functions as a transposable element. Molecular and General Genetics 203, 79-88.

Lydiate, D. J., Henderson, D. J., Ashby, A. M. \& HopwOOD, D. A. (1987). Transposable elements of Streptomyces coelicolor A3(2). In Genetics of Industrial Micro-organisms, Part B, pp. 49-56. Edited by M. Alacevic, D. Hranueli \& Z. Toman. Zagreb: Pliva.
Lydiate, D. J., Mendez, C., Kieser, H. M. \& HopwoOD, D. A. (1988). Mutation and cloning of clustered Streptomyces genes essential for sulphate metabolism. Molecular and General Genetics 211, 415-423.

Madon, J., Moretti, P. \& Hütter, R. (1987). Sitespecific integration and excision of pMEA 100 in Nocardia mediterranei. Molecular and General Genetics 209, 257-264.

Malpartida, F., Hallam, S. E., Kieser, H. M., Motamedi, H., Hutchinson, C. R., Butler, M. J., Sugden, D. A., Warren, M., MCKILlop, C., BaIley, C. R., Humphreys, G. O. \& HoPwOOd, D. A. (1987). Homology between Streptomyces genes coding for synthesis of different polyketides used to clone antibiotic biosynthesis genes. Nature, London 325, 818-821.

Maniatis, T., Fritsch, E. F. \& SAmbrook, J. (1982). Molecular Cloning: a Laboratory Manual. Cold Spring Harbor, NY: Cold Spring Harbor Laboratory Press.

Murray, N. E., Brammar, W. J. \& Murray, K. (1977). Lambdoid phages that simplify the recovery of in vitro recombinants. Molecular and General Genetics 150, 53-61.

Rodicio, M. R., Bruton, C. J. \& Chater, K. F. (1985). New derivatives of the Streptomyces temperate phage $\phi \mathrm{C} 31$ useful for the cloning and functional analysis of Streptomyces DNA. Gene 34, 283-292.

RÜTher, U., KOENEN, M., OTTO, K. \& MÜlLER-HILl, B. (1981). pUR222, a vector for cloning and rapid chemical sequencing of DNA. Nucleic Acids Research 9, 4087-4098.

Seno, E. T., Bruton, C. J. \& Chater, K. F. (1984). The glycerol utilization operon of $S$. coelicolor: genetic mapping of $g y l$ mutations and the analysis of cloned gyl DNA. Molecular and General Genetics 193, 119-128.

Smith, C. P. \& Chater, K. F. (1988). Cloning and transcription analysis of the entire glycerol utilisation $(g y l A B X)$ operon of $S$. coelicolor $A 3(2)$ and identification of a closely associated transcription unit. Molecular and General Genetics 211, 129-137.

Soberon, X., Covarrubias, L. \& Bolivar, F. (1980). Construction and characterization of new cloning vehicles. IV. Deletion derivatives of pBR322 and pBR325. Gene 9, 287-305.

VIVIAN, A. \& HoPwoOd, D. A. (1970). Genetic control of fertility in Streptomyces coelicolor A3(2): the IF fertility type. Journal of General Microbiology 64, 101-117.

Vivian, A. \& Hopwood, D. A. (1973). Genetic control of fertility in Streptomyces coelicolor A3(2): new kinds of donor strains. Journal of General Microbiology 76, 147-162.

Yanisch-Perron, C., Vieira, J. \& Messing, J. (1985). Improved M13 phage cloning vectors and host strains: nucleotide sequences of the M1 $3 \mathrm{mpl} 18$ and pUC19 vectors. Gene 33, 103-119. 